\title{
Mucosal metaplasia in the appendix
}

\author{
J. B. MacGILLIVRAY \\ From the Department of Pathology, Maryfield Hospital, Dundee
}

SYNOPSIS Metaplastic foci do not appear to have been previously described in the mucosa of the appendix. Eight examples are reported, two of which were found in a series of 100 consecutive appendicectomies.

Metaplastic foci occur commonly as grossly visible nodules in the large intestinal mucosa, especially in the rectum, over the age of 40 ; these are described and well illustrated by Arthur (1968). The occurrence of comparable foci of metaplasia in the appendix does not appear to have been reported. The unexpected finding of six examples in routine appendicectomy specimens prompted a further search.

\section{Materials and Methods}

One hundred consecutive appendices were examined by taking a longitudinal block from the tip and nine to 15 blocks, 3 to $4 \mathrm{~mm}$ thick, from the rest of the organ. One section from each block was stained by haematoxylin and eosin. A longitudinal section of the tip of the appendix and at least one transverse section stained by haematoxylin and eosin were available of the appendices previously collected.

\section{Results and Pathology}

Two of the 100 consecutive appendices examined contained patches of mucosal metaplasia covering about $3 \mathrm{~mm}$ of the mucosal surface on transverse Received for publication 25 April 1972. section, each in a single block from the body of the appendix (Table, cases 1 and 2). A rough estimate was also made of the size of the lesions in the sections which were available of the six appendices previously collected (Table). None of the eight lesions was noted on gross examination.

The metaplastic foci are made up of glands whose deeper lining resembles normal appendicular epithelium, containing hyperchromatic nuclei showing numbers of mitotic figures. Towards the lumen the glands become dilated and lined by goblet cells and cells with pink staining cytoplasm and pale vesicular nuclei with only an occasional mitotic figure. Variation in height and papillary infolding of these cells gives a characteristic serrated appearance to the epithelial lining (Figs. 1 and 2). In case 6 (Table) an additional finding was a villous adenoma at the tip of the appendix. Its extent and relation to the metaplasia in the body of the appendix is uncertain, but in parts of the adenoma the mucosa shows foci of characteristic metaplasia (Fig. 3).

Only two of the eight appendices were acutely inflamed (Table, cases 7 and 8). The remainder were removed because of right iliac fossa pain or incidentally during the course of some surgical procedure (Table).

\begin{tabular}{|c|c|c|c|c|c|}
\hline Case No. & Age and Sex & Site & Size $(\mathrm{mm})$ & Indication for Operation & Comments \\
\hline 1 & F70 & Body & 3 & Abdominoperineal resection for carcinoma of rectum & No inflammation \\
\hline 2 & F58 & Body & 3 & Incisional hernia & No inflammation \\
\hline 3 & M32 & Tip & 8 & Intermittent right iliac fossa pain for 5 yr & No inflammation \\
\hline 4 & F47 & Body & 4 & Pain in right iliac fossa and nausea & No inflammation \\
\hline 5 & M58 & Tip & 9 & Staging laparotomy for carcinoma of prostate & No inflammation \\
\hline 6 & M69 & Body & 6 & Right hemicolectomy for carcinoma of ascending colon & $\begin{array}{l}\text { No inflammation; } \\
\text { villous adenoma at } \\
\text { tip of appendix }\end{array}$ \\
\hline 7 & F60 & Tip & 3 & Acute appendicitis with peritonitis & Inflamed appendix \\
\hline 8 & M60 & $\begin{array}{l}\text { Tip and } \\
\text { body }\end{array}$ & ? & Acute appendicitis & $\begin{array}{l}\text { Inflamed appendix } \\
\text { with faecolith }\end{array}$ \\
\hline
\end{tabular}




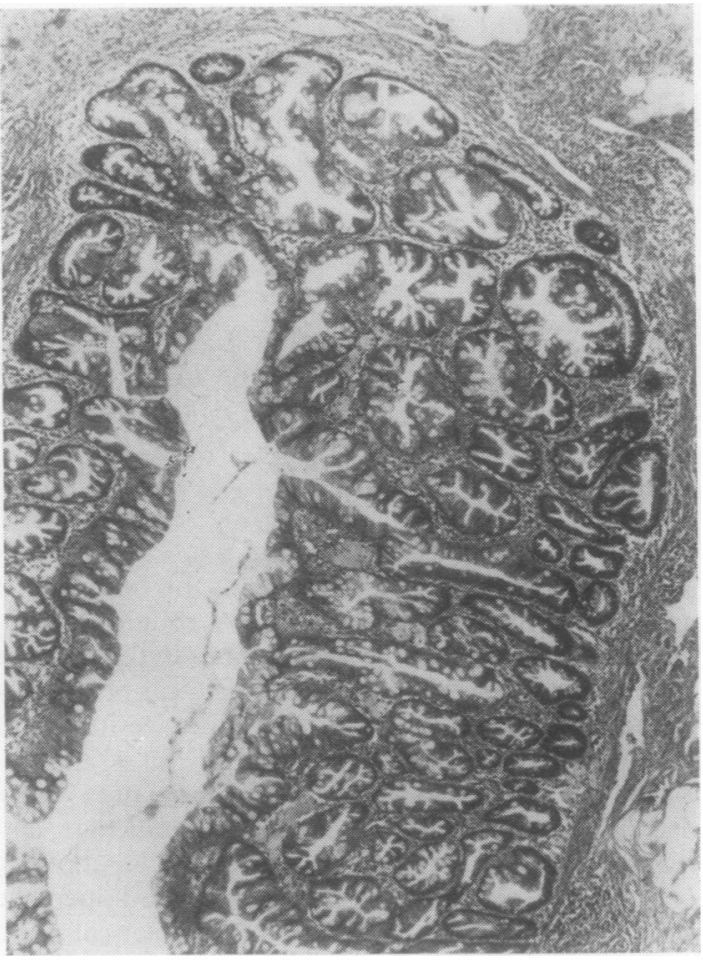

Fig. 1 Case 3: metaplastic nodule at the tip of the appendix containing dilated glands with papillary infolding of their lining epithelium. $H$ and $E \times 40$.

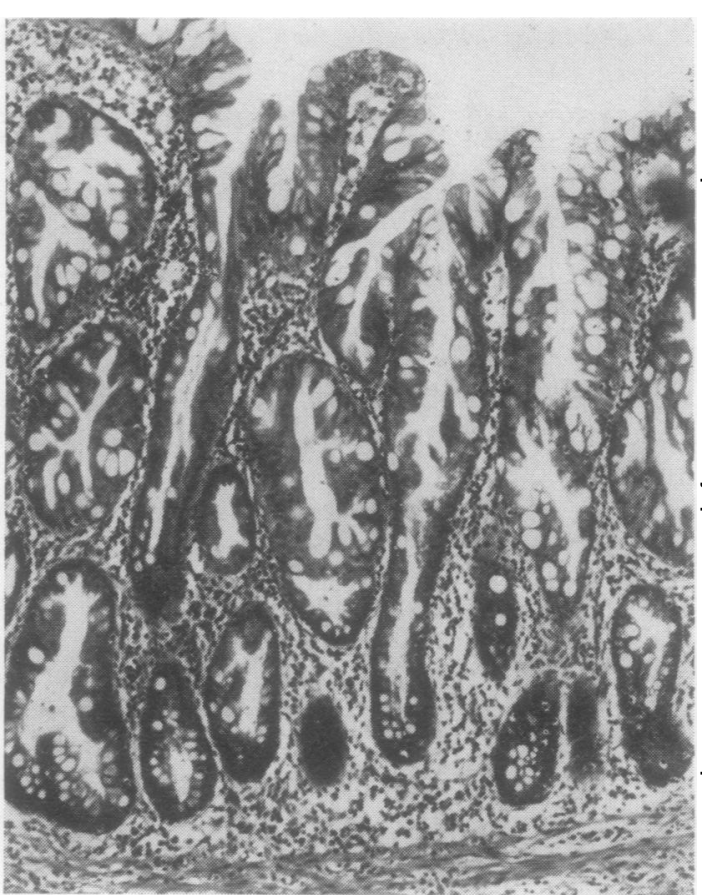

윰

Fig. 2 Case 3: a higher magnification shows the change in appearance of the glands towards the lumen of the appendix. Note the paler staining epithelium with a serrated appearance and the dilated lumina. $H$ and $E$, 100.

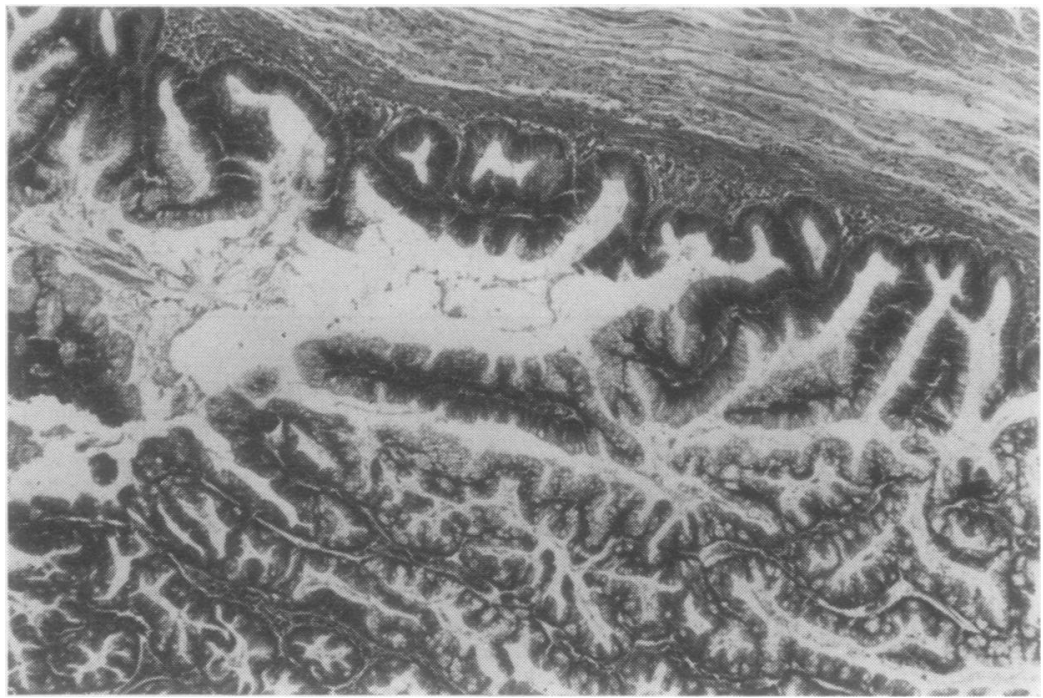

Fig. 3 Case 6: villous adenoma at the tip of the appendix. At the top right some of the glands resemble those in metaplastic nodules. $H$ and $E \times 50$. 


\section{Discussion}

Collins (1963), who examined 71000 appendicectomy specimens, refers to 57 benign epithelial polyps of the appendix but does not give further details, and Hameed (1966) does not mention metaplastic nodules in his review of epithelial polyps of the appendix.

The histological appearance of the appendicular foci is similar to that found in the large bowel nodules (Lane and Lev, 1963; Arthur, 1968; Lane, Kaplan, and Pascal, 1971).

In the large bowel, metaplastic or hyperplastic nodules are considered to be distinct from adenomatous polyps (Lane, Kaplan, and Pascal. 1971), but areas of metaplasia identical with that in the nodules may be present in villous adenomas (Table, case 6). Goldman, Ming, and Hickok (1971) found metaplasia in 10 of 63 villous adenomas in the colon and suggest that some villous adenomas may be derived from metaplastic nodules.

Further evidence of a possible relation between the two lesions is their similar enzyme patterns, in particular reduced succinic dehydrogenase, compared to adenomatous polyps which show increased succinic dehydrogenase activity (Czernobilsky and Tsou, 1968).

Despite the foregoing, metaplastic nodules are generally considered to be degenerative in nature rather than neoplastic and a common finding in the colon of older people (Arthur, 1968).

Although the number of cases in this series is small, most of the lesions were found in normal appendices and they do not appear to be associated with acute appendicitis.

\section{References}

Arthur, J. F. (1968). Structure and significance of metaplastic nodules in the rectal mucosa. J. clin. Path., 21, 735-743.

Collins, D. C. (1963). 71,000 human appendix specimens. A final report summarizing forty years study. Amer. J. Proctol., 14, 265-281.

Czernobilsky, B., and Tsou, K. C. (1968). Adenocarcinoma, adenomas and polyps of the colon. Histochemical study. Cancer (Philad.), 21, 165-177.

Goldman, H., Ming, S., and Hickok, D. F. (1970). Nature and significance of hyperplastic polyps of the human colon. Arch. Path., 89, 349-354.

Hameed, K. (1966). Epithelial polyps of the vermiform appendix-a review. Amer. J. Gastroent., 46, 339-346.

Lane, N., Kaplan, H., and Pascal, R. R. (1971). Minute adenomatous and hyperplastic polyps of the colon: Divergent patterns of epithelial growth with specific associated mesenchymal changes. Gastroenterology, 60, 537-551.

Lane, N., and Lev, R. (1963). Observations on the origin of adenomatous epithelium of the colon. Serial section studies of minute polyps in familial polyposis. Cancer (Philad.), 16, 751764. 